\title{
Generando la inocencia: creación, uso e implicaciones de la identidad de «inocente» en los periodos de conflicto y posconflicto en el Perú
}

Engendrer l'innocence : la création, l'utilisation et les implications de l'identité d'«innocent» durant les périodes de conflit et de post-conflit au Pérou Generating innocence: creation, use and implications of the identity of «innocent» in the conflict and post-conflict periods in Peru

\section{Marie J. Manrique}

\section{OpenEdition}

Journals

Edición electrónica

URL: http://journals.openedition.org/bifea/4313

DOI: $10.4000 /$ bifea.4313

ISSN: 2076-5827

Editor

Institut Français d'Études Andines

Edición impresa

Fecha de publicación: 1 mayo 2014

Paginación: 53-73

ISSN: 0303-7495

Referencia electrónica

Marie J. Manrique, « Generando la inocencia: creación, uso e implicaciones de la identidad de «inocente» en los periodos de conflicto y posconflicto en el Perú », Bulletin de l'Institut français d'études andines [En línea], 43 (1) | 2014, Publicado el 08 mayo 2014, consultado el 05 noviembre 2020. URL http://journals.openedition.org/bifea/4313 ; DOl : https://doi.org/10.4000/bifea.4313

\section{(c) (†) $९$}

Les contenus du Bulletin de l'Institut français d'études andines sont mis à disposition selon les termes de la licence Creative Commons Attribution - Pas d'Utilisation Commerciale - Pas de Modification 4.0 International. 


\title{
Generando la inocencia: creación, uso e implicaciones de la identidad de «inocente» en los periodos de conflicto y posconflicto en el Perú
}

\author{
Marie J. Manrique*
}

\begin{abstract}
Resumen
El término «los inocentes» se refiere a las personas sentenciadas por delitos de terrorismo durante el conflicto armado interno en el Perú que solicitaron un indulto a través de un mecanismo extrajudicial creado por el Estado entre 1996 y 2002. Este artículo explora esta identidad, cómo fue determinada y su proceso de producción. Identifica factores relacionados a la construcción del fenómeno y explora las características transversales de este posicionamiento: la práctica de la fe religiosa, los espacios ocupados y las actividades realizadas dentro del penal, los estereotipos de género, etnia y otras. A su vez, contribuye a las investigaciones sobre el conflicto, enriqueciendo el entendimiento de su complejidad y revelando las narrativas elaboradas.
\end{abstract}

Palabras claves: cárceles, conflicto armado interno, terrorismo, construcción de identidades, espacio, lugar

Engendrer l'innocence : la création, l'utilisation et les implications de l'identité d'«innocent» durant les périodes de conflit et de post-conflit au Pérou

\section{Résumé}

Le terme «les innocents» fait référence aux personnes condamnées pour terrorisme pendant le conflit armé interne au Pérou qui sollicitèrent une grâce au moyen d'un mécanisme extrajudiciaire créé par l'État entre 1996 et 2002. Cet article explore cette identité, comment elle a été déterminée et son 
processus de production. II identifie les facteurs liés à la construction du phénomène et explore les caractéristiques transversales de ce positionnement : la pratique de la foi religieuse, les espaces occupés et les activités réalisées en prison, les stéréotypes de genre, d'ethnie et d'autres. Il contribue ainsi à la recherche sur le conflit, enrichit la compréhension de sa complexité et révèle les métarécits élaborés.

Mots-clés: prisons, conflit armé interne, terrorisme, construction identitaire, espace, lieu

\title{
Generating innocence: creation, use and implications of the identity of «innocent» in the conflict and post-conflict periods in Peru
}

\begin{abstract}
The term «the innocents» refers to people sentenced for crimes of terrorism during the internal armed conflict in Peru who requested a pardon through an extrajudicial mechanism created by the State between 1996 and 2002. This essay explores this identity, how it was determined and its process of production. It identifies factors related to the construction of the phenomenon and explores the following cross-cutting characteristics of this positionality: the practice of religious faith, spaces occupied and activities conducted in prison, stereotypes of gender, ethnicity and others. It contributes to research on the conflict, enriching the understanding of its complexity and revealing the narratives produced.
\end{abstract}

Keywords: prisons, internal armed conflict, terrorism, identity construction, space, place

«¿¿C]ómo saber con certeza qué fue voluntario y por simpatías y qué por la fuerza o bajo amenaza? ¿Hay un límite exacto que permita separar lo voluntario de lo involuntario? ¿Cuándo se puede decir que la persona fue parte de y cuándo fue víctima de? ¿Qué versión creer y cuál no?»

Ernesto de la Jara

«Desgraciadamente, no existe una aureola luminosa que permita distinguir, a primera vista, un auténtico inocente de otro que pretende serlo»

Hubert Lanssiers

\section{A CONFESIÓN DE PARTE, RELEVO DE PRUEBA}

El fenómeno de «los inocentes», como muchos aspectos relacionados al conflicto armado interno en el Perú (1980-2000), está cargado de emociones diversas, opiniones divergentes y cierta reticencia a profundizar. «Inocente» es la denominación dada a las personas que fueron sentenciadas por delitos de 
terrorismo 1 , que solicitaron y lograron su indulto (derecho de gracia para quienes estaban en calidad de procesados) entre 1996 y 2002 a través de un mecanismo extrajudicial creado por el Estado.

Cuando comenté mi tema de estudio a personas vinculadas a esta problemática, surgieron una serie de reacciones: miradas de suspicacia, preguntas sobre la motivación y/o advertencias de «no ser el mejor momento» para abordar el tema. Se cuenta con poco análisis realizado sobre la creación de esta categoría, sus usos e implicancias desde la década de 1980 hasta el presente. Tal vez por eso, durante este examen del tema, para usar una analogía de las etapas de investigación del proceso penal, me he sentido como una imputada citada a explicar mis móviles, lo que implica tener un adecuado descargo, para salir bien librada del interrogatorio. El año 2001, Ernesto de la Jara Basombrío publicó su gran estudio sobre los inocentes, Ilamado Memoria y batallas en nombre de los inocentes. Perú, 19922001, el cual proporciona un análisis jurídico, político, social y cultural de la existencia de esta categoría y las acciones realizadas por los organismos de derechos humanos respecto al tema, desde 1992 hasta el fin del gobierno de transición (De La Jara, 2001). Un año antes, la Defensoría del Pueblo había publicado su informe final sobre la Comisión Ad-Hoc (CAH) con los datos (decretos, procedimientos, cifras y nombres) recogidos durante sus 40 meses de existencia (Defensoría del Pueblo, 2001 [2000]). Además de estos textos, hay algunos ensayos sobre los inocentes en relación a la salud mental. Existen también otras investigaciones, más profundas, sobre la experiencia carcelaria de las personas sentenciadas por delitos de terrorismo, pero éstas se hallan centradas en lo que el Partido Comunista del Perú - Sendero Luminoso (PCP-SL) Ilamó sus «luminosas trincheras de combate».

Sin embargo, el trasfondo todavía candente del terrorismo, directamente relacionado con la pregunta clave de quiénes eran (y/o son) «los inocentes» (personas sospechosas, detenidas, procesadas, sentenciadas y/o indultadas por este delito), enturbia una búsqueda rigurosa de respuesta a esta interrogante. El concepto de «terrorismo» es provocador, lo que hace que los espacios para examinar la producción y uso de la «inocencia» sean mínimos, ya que esta categoría (no solamente la identidad) tiende a estar cargada de intereses y posicionamientos en una sociedad que no solo sobrevivió a un conflicto con el saldo humano de casi 70000 muertos, sino que intenta sobreponerse a sus secuelas.

La prudencia de la actualidad («no es el mejor momento») se asemeja a lo señalado por De La Jara, al referirse a los riesgos de la iniciativa de poner en la agenda política el tema de «los inocentes en prisión» a mediados de los años 1990, pues quien lo hacía, «inmediatamente era acusado de cómplice del terrorismo y corría el riesgo de estar ganándose su propio traje a rayas» (De La Jara, 2001: 27). Con el proyecto de ley sobre el «negacionismo» de los delitos de terrorismo (léase

1 Se empleará este término para referirse a los delitos de terrorismo, traición a la patria y delitos conexos. 
de las organizaciones subversivas), presentado por el gobierno al Congreso de la República a finales de agosto de 20122, sigue el debate sobre cómo un Estado de Derecho debe afrontar al terrorismo del pasado y garantizar su no repetición, respetando y protegiendo otros derechos.

Este ensayo forma parte de las investigaciones sobre aspectos previamente ocultos del conflicto que enriquecen el entendimiento de su complejidad y para lo cual es útil identificar los procesos de construcción de identidades y narrativas relacionadas con éste. Se explora la construcción de la inocencia para reflexionar sobre cómo fue determinada y cuál fue su proceso de producción, examinando algunas características - transversales - que fueron determinantes (o no) de esta posicionalidad: la práctica de la fe religiosa, los espacios ocupados y las actividades realizadas dentro de las prisiones, los estereotipos de género y étnicos, entre otros.

El análisis se centra en la producción de la «inocencia» y tiene los siguientes objetivos: contribuir al entendimiento más matizado de los contornos del conflicto, promover perspectivas múltiples sobre cómo afrontar los desafíos del posconflicto, y finalmente, intentar ir más allá de las explicaciones convencionales, los mitos y los tropos sobre los orígenes y actores de la violencia política en el país. La verdad no es singular. En muchos contextos de posconflicto, el esfuerzo para recordar colectivamente los hechos — no se debe ignorar que hay personas que no han podido darse el lujo de olvidarlos - frecuentemente se convierte en el establecimiento de un nuevo paradigma que no siempre es el más idóneo.

Los silencios, la memoria selectiva y la negación de las verdades múltiples dan lugar a una historia homogeneizadora, simplificada, digerible, pero no necesariamente la hacen más precisa o libre de contiendas. El desarrollo del concepto y accionar alrededor de los «inocentes» lo demuestra. En su estudio de memorias en Italia posfascista, Alessandro Portelli escribe que «existe sólo un nombre para denominar una creencia más fuerte que la prueba y la información: mito» (Portelli, 2003: 182). Por lo tanto, este ensayo es una tentativa de explorar cómo algunos mitos alrededor de la categoría de «inocentes» fueron elaborados y empleados.

\section{NACIDO INOCENTE}

El Perú cuenta con una categoría jurídico-política sui generis. Bajo un término colectivo, casi siempre en masculino, existía (y existe) un grupo de personas nombradas «los inocentes». De la Jara refiere a este grupo como «inocentes en prisión acusados injustamente de terrorismo» que eran «miles y miles de personas arrancadas de su casas, encarceladas, humilladas, exhibidas, torturadas y, al final, después de semanas, meses o años de prisión, la mayoría liberadas... porque eran inocentes» (De La Jara, 2001: 23). Aunque la cifra no llega a mil, habla de «miles

2 Al momento de redactar, todavía era un proyecto de ley, y su entusiasmo por aprobarlo parece haberse ido diluyendo con el tiempo. 
y miles». La exageración muestra la manera cómo esta identidad fue construida con posterioridad a $1992^{3}$.

Aunque antes de 1992 hubo personas que podrían haber entrado en esta categoría — si bien su cuantía era menor-, el término «inocentes» en colectivo surgió desde las circunstancias creadas tras el autogolpe de Fujimori en abril de 1992. Inmediatamente después, en el mes de mayo, se emitieron las primeras leyes que establecían nuevas tipologías, procedimientos y penas para los delitos de terrorismo (Decreto Ley 25475, 6 de mayo de 1992) y traición a la patria (Decreto Ley 25659, 12 de agosto de 1992). Estos dispositivos instalaron la cadena perpetua, el fuero militar para juzgar civiles, jueces y fiscales «sin rostro» y otras violaciones a la garantía del debido proceso.

Una combinación de factores relacionados llevaron a que el número de personas privadas de libertad creciera exponencialmente: 1) la severidad de la legislación; 2) el proceder estatal en las detenciones que hizo de la tortura física y psicológica un modus operandi; 3) la ofensiva de una fuerza policial que había ido acumulando información de inteligencia estratégica; y 4) la vigencia entre mayo de 1992 y noviembre de 1994 de una ley de arrepentimiento (Decreto Ley 25499, 16 de mayo de 1992) que otorgó beneficios a las personas que señalaban a otras supuestamente culpables del delito de terrorismo.

Con el conflicto llegando a sentirse ampliamente en Lima y el auge de las políticas dictatoriales de Fujimori, hubo poco espacio político a nivel nacional para cuestionar la validez de la legislación. No obstante, entre 1994 y 1996 hubo 8 proyectos para modificarla (Asociación Nacional de Inocentes Liberados, s. f.). El incremento desmesurado de detenciones y las violaciones flagrantes al debido proceso contribuyeron a la promulgación de la Ley 26655, publicada el 16 agosto de 1996, que creó una «Comisión Ad-Hoc $(\mathrm{CAH})$ para evaluar, calificar y proponer, en forma excepcional, la concesión del indulto o el derecho de gracia presidencial para las personas procesadas o condenadas por terrorismo y traición a la Patria» (Ley 26655, 16 de agosto de 1996), la cual fue conformada por el representante de Fujimori, el Padre Hubert Lanssiers, el primer defensor del pueblo Jorge Santistevan de Noriega y el entonces ministro de Justicia Carlos Hermoza Moya. La CAH tuvo el encargo de recomendar al Presidente de la República el otorgamiento del indulto o derecho de gracia a las personas que, en opinión de la Comisión, «no habrían tenido ningún tipo de vinculación con elementos, actividades u organizaciones terroristas» (Ley 26655, 16 de agosto de 1996).

Durante el período de su existencia (20 agosto de 1996 al 31 diciembre de 1999), 502 personas fueron liberadas bajo estas dos modalidades. En 1999, las labores de la CAH fueron encomendadas al Consejo Nacional de Derechos Humanos

3 Según De la Jara (2001: 241), las cifras del Registro Único de Detenidos (RUD) y aquellas del Instituto Nacional Penitenciario (INPE) no son siquiera aproximadas. En agosto de 1996, el INPE indica que hubo 3878 detenidos por terrorismo y traición a la patria, mientras que el RUD indica que hubo 12916 detenidos puestos a disposición de justicia entre 1992 y 1996, resultando en una diferencia de 9038 personas, algo que De la Jara atribuye a detenidos, condenados y absueltos. 
del Ministerio de Justicia con una lista prioritaria de 246 personas a la espera del indulto. De esta lista, Fujimori firmó 21 resoluciones de indultos (2 casos el 28 de enero de 2000 y 19 casos el 27 de julio de 2000) (De La Jara, 2001: 608). Tras la caída de Fujimori, este consejo propuso el indulto para 264 personas (CVR, 2003, Tomo VI: 428). El gobierno de Valentín Paniagua indultó a 46 personas y el de Alejandro Toledo 220 más (Crónica Viva, 2010). En total, 789 personas salieron de la cárcel bajo esta figura excepcional en la historia penal. Recibieron un indulto que los reconocía como «inocentes» en un proceso extrajudicial. Se consideraban inocentes y, después de una revisión minuciosa de sus expedientes y un proceso multifacético —no necesariamente ligado a los procedimientos característicos de una investigación penal— fueron respaldados en esta aseveración.

\section{3. ¿HIJO NO RECONOCIDO?}

En el derecho se habla de «filiatio non potest probari» para señalar que no se puede determinar la filiación de un/a hijo/a. De una manera similar, no existe un engendrador del «inocente»; cada grupo señala a otro como el padre de la criatura. Según el presidente de la Asociación de Reflexión de Inocentes Liberados (ARIL), Edgar Rivadeneyra, «la gente que trabajaba en los penales llevó este discurso adentro» (Rivadeneyra, 17 de agosto de 2012). Una abogada de la ONG que presentaba casos a la $\mathrm{CAH}$, que prefiere permanecer en el anonimato, indicó que fue «un reclamo de la población carcelaria»(BB, 28 de agosto de 2012). De la Jara reconoce que el origen de la campaña «en nombre de los inocentes» venía de los organismos de derechos humanos, sin precisar si esta «(in) feliz muletilla» incluía la responsabilidad por la concepción del término (De La Jara, 2001: 28). En la ceremonia del cierre de la Comisión Ad-hoc, el secretario técnico de la comisión Gino Costa Santolalla, agradeció «a las instituciones de Derechos Humanos, cuyo trabajo abrió el camino a la creación de la Comisión y cuyos esfuerzos han facilitado y complementados los nuestros» (CAH, 30 de diciembre de 1999). Aunque las partes prefieran tomar distancia de la acuñación del término, lo más adecuado es entender su procedencia como una producción conjunta y dinámica, entre discursos de las personas en la cárcel, defensores/as de derechos humanos en la calle y entes estatales intentando defenderse de la crítica nacional e internacional.

La identidad de «inocente» se fue transformando según el contexto y el momento. Mientras que las ONG tenían la «penosa necesidad de elaborar argumentos sin ser golpeadas» durante la época fujimontesinista, con el transcurrir del tiempo y la recuperación de la democracia surgieron otros discursos alrededor de «los inocentes» (Rivadeneyra, 13 de diciembre de 2010). La defensora de derechos humanos Pilar Coll las definió como personas a las que «no se pudo probar... un acto delictivo», reconociendo que no eran «puros e inmaculados» (Coll, 10 de diciembre de 2010). De la Jara, aceptando que en la campaña «priorizamos aspectos prácticos», recalcó que «no hemos sacado a nadie que tenía una responsabilidad mínimamente grave» (De La Jara, 1 de diciembre de 2010). 
Para esta investigación se utilizaron los expedientes de personas solicitantes de un indulto a través de la CAH que se encuentran en el Centro de Información para la Memoria Colectiva y los Derechos Humanos luego del traslado de gran parte del acervo documental de la CAH al Consejo Nacional de Derechos Humanos del Ministerio de Justicia, el 31 de diciembre de 19994. De igual manera, se usaron los documentos internos de la CVR que registraron las interacciones, conversaciones y actividades realizadas con las personas privadas de libertad. Aunque la posibilidad de un indulto había pasado, algunos/as testimoniantes replantearon la inocencia dentro del contexto de los nuevos juicios que empezaron en 20035. En un documento interno, el equipo responsable de la toma de testimonios en los penales señaló:

Respecto a inocentes en prisión, al parecer la depuración que se hizo de ellos por la Comisión de Indultos y después por la Comisión del Ministerio de Justicia ha sido bastante precisa y si quedasen algunos, serían muy pocos (CVR, «Plan ad hoc...», s. f., Expediente SCO36001).

\section{EL GUIÓN DE LA INOCENCIA Y SU ELENCO}

La identidad siempre es fluida. Sin embargo, los esquemas y enfoques arraigados en tradiciones humanistas clásicas, que esencializan a personas, tienden a reificar identidades, debido a su supuesta «esencia», como si fueran fijas e inalterables. No obstante, si se acepta que no existen categorías esenciales que definen y delimiten identidades y más bien son construcciones sociales, se entiende que la identidad es cambiante dependiendo del contexto; es decir, es dinámica y mutable.

Los estudios de género igualmente han enseñado que el género y sexo son performativos; se considera que la inocencia también es performativa. Judith Butler escribe:

El acto que una hace, el acto que una realiza, es, en cierto sentido, un acto que ha estado ocurriendo antes de que una llegó a la escena. Por lo tanto, el género es un acto que ha sido ensayado, tanto como un guión sobrevive a los actores particulares que hacen uso de ello, pero requiere actores individuales para ser actualizado y ser reproducido como realidad de nuevo (Butler, 1990).

La identidad de inocente no era estable. Una persona que podía haber tenido una responsabilidad mínima en un acto delictivo de subversión, luego de un análisis

4 En el año 2001, De la Jara señaló que, «hasta hoy, la información disponible sobre detención y juzgamiento por terrorismo sigue siendo medio clandestina; por alguna razón, se sigue creyendo que atestados policiales, sentencias, incidentes de arrepentimiento, deben mantenerse escondidos y hasta enterrados. Por algo será» (De La Jara, 2001: 33). A pesar de la existencia de la ley de habeas data y el principio de publicidad de sentencias ejecutoriadas, el acceso al acervo documental en la materia genera ciertos desafíos.

5 Los «nuevos» juicios fueron dados en cumplimiento del fallo del Tribunal Constitucional (Exp. n. ${ }^{\circ}$ 0001-2002-Al Lima, 2003) que declaró inconstitucionales algunos aspectos de la legislación antiterrorista dictada en mayo de 1992. 
extralegal de su proceso judicial desde la detención hasta el dictado de la sentencia, con una exploración social de su «carácter», podía ser designada inocente (o podía ella misma considerarse como tal). Años después, esta misma persona podía replantear su pasado. El mismo Padre Lanssiers, en el cierre de la $\mathrm{CAH}$, advirtió que «la gente es capaz de cambiar. Todos aquellos que se han desvinculado» son personas que también merecían atención (CAH, 30 de noviembre de 1999). La definición de inocencia no solamente se mutaba según el momento histórico y las transformaciones individuales, también fue modificándose sobre la base de los actos performativos imbricados en los espacios donde fueron puestos en escena.

Según el reglamento de la $\mathrm{CAH}$, los criterios utilizados para formular sus recomendaciones tomaban en cuenta:

a) Hechos imputados. b) Circunstancias de la detención. c) Características del procedimiento observado durante la etapa policial y judicial. d) Conducta durante el período de privación de libertad. e) Situación personal, familiar, cultural y social del solicitante. f) Trayectoria personal del posible beneficiario (Ley 26655, 16 de agosto de 1996).

En un comunicado de febrero de 1997, la CAH expresó que consideraba:

[los] antecedentes personales de cada solicitante, la conducta observada durante su detención, los elementos probatorios que obran en el proceso judicial correspondiente, así como el resultado de las entrevistas personales llevadas a cabo en la mayoría de los casos por los miembros de la Comisión y los testimonios facilitados por las autoridades penitenciarias» $(\mathrm{CAH}, 14$ de febrero de 1997).

Los expedientes que proponían al presidente, contenían una sección con los fundamentos de la petición, que incluía los hechos, las razones y las evidencias. La recomendación de indulto se motivaba en la revisión de la uniformidad (o no) de declaraciones desde la detención hasta ese entonces, de los medios de prueba y del valor probatorio. Luego seguían tres secciones adicionales que consistían en la entrevista personal, la conducta observada en el penal, y «otras investigaciones». La atención se enfocó en este último grupo - llamado en la ficha de algunos expedientes como «indagación y comprobación extrajudicial» (CAH, 021-99/ $\mathrm{CAH}$ - ya que se le considera ilustrativo por la manera en que se construía esta identidad y posteriormente, por cuáles han sido, y son, sus implicancias.

Hubo características saltantes que surgen en las solicitudes, las cuales contribuyeron a determinar si el indulto era o no procedente. En las siguientes secciones, se realizará un enfoque en algunas de las nociones extralegales empleadas para crear y performar la inocencia: la fe religiosa, los espacios ocupados y las acciones realizadas dentro del penal, los estereotipos de género y otras características.

\section{DIME DÓNDE ANDAS Y TE DIRÉ QUIÉN ERES}

La construcción de la identidad es un proceso dinámico con lo cual su producto también es cambiante. Dado que una parte fundamental de la revisión para determinar el otorgamiento (o no) del indulto fue la manera en la cual el/la 
solicitante se presentaba, así como su conducta en el penal, es útil problematizar a las personas y su relación con los espacios carcelarios. Las identidades fueron construidas a través de lugares, y en un proceso concurrente e interdependiente los lugares fueron construidos a través de identidades.

Este análisis se basa en la distinción entre el «espacio» físico como algo neutral de significados versus el «lugar», que es imbuido por sentidos, sentimientos, posicionamientos, etc. (Tuan, 2011 [1977]). Actualmente estas ideas están muy difundidas y han sido exploradas en varias disciplinas como la Geografía, Antropología y Estudios Urbanos. Hay, además, una vasta literatura sobre los lugares de la memoria. Al hablar de inocentes, es necesario aproximarse a «[l]a manera en que espacios y lugares se construyen, están imaginados, discutidos e impuestos [enforced]» (Gupta \& Ferguson, 1992: 18).

Durante los difíciles años del régimen cerrado, en los dos penales limeños (E. P. Miguel Castro Castro, para los varones, y el Anexo de Máxima Seguridad del Penal Santa Mónica de Chorrillos, para las mujeres) que albergaban a prisioneros/as por delitos de terrorismo, la Iglesia Católica (particularmente el Padre Lanssiers y la Hermana Marie Madeleine Wartelle) junto con las autoridades estatales (principalmente a través de la policía que en ese momento controlaba ambas prisiones), impulsaron la creación de pabellones pilotos en los cuales vivían, trabajaban, profesaban su fe y recibían visitas las personas nombradas y autodenominadas «inocentes». Posteriormente, otros internos desvinculados de los grupos subversivos también se ubicarían en estos pabellones. Estos espacios físicos —el pabellón A en Chorrillos e inicialmente el Venusterio y luego el pabellón 1-A en Castro Castro— se convirtieron en «lugares de inocencia».

A través del uso e interacción en las celdas, los pasadizos, el patio y eventualmente los talleres, los internos, las personas e instituciones que los apoyaban y acompañaban, así como las autoridades, proyectaron a estos espacios físicos significados casi tan primordiales como el encierro mismo: era un panel luminoso y la escenificación de la inocencia. Las personas que vivían en otros pabellones contribuyeron como actores de reparto.

De la misma forma que «las luminosas trincheras de combate» del PCP-SL, investigadas por José Luis Renique, fueron parte de una performance (Renique, 2003), estos «lugares de inocencia» sirvieron como un escenario en el cual un guión pudo «ser actualizado y ser reproducido como realidad de nuevo» (Butler, 1990). En cada espacio la identidad fue grabada y el lugar inscrito en la identidad.

Casi todos los expedientes consultados enfatizan el espacio que el/la solicitante ocupaba en el penal. Como indica una abogada:

Objetivamente se tomaba en cuenta en qué pabellón vivía. [Del penal de mujeres de Chorrillos] Pabellón C- nada. Pabellón B- nada (BB, 28 de agosto de 2012).

Algunas de las solicitudes realizadas desde el Penal Castro Castro no hacían mención de su ubicación más allá de «pabellón piloto» (CAH, informe n. $\left.{ }^{\circ} 007-96 / C A H\right)$. Esta localización fue uno de los factores medulares en un expediente exitoso: 
La solicitante, a su llegada al Penal, estuvo recluida en el Pabellón ' $\mathrm{C}^{\prime}$; luego de un proceso de selección pasó al Pabellón ' $\mathrm{A}$ ', que alberga a internas de menos peligrosidad (CAH, informe $\left.n .^{\circ} 001-97 / C A H\right)$.

Y otro:

El solicitante se encuentra ubicado en el Pabellón 1-B que alberga a internos considerados independientes e integrantes de la Comunidad Cristiana (CAH, informe n. ${ }^{\circ}$ 005-99/CAH).

En las solicitudes de indulto archivadas, los lugares fuera de los «pabellones piloto» o espacios que ocuparan los de autodenominados «inocentes», servían como marca de la no inocencia o incluso, dependiendo de la perspectiva, de culpabilidad:

Él se encuentra ubicado en el pabellón 4B, calificado de 'máxima seguridad', ya que alberga a internos que apoyan a la guerra popular y a internos que apoyan el Acuerdo de Paz (CAH, informe archivado, 24 de abril de 1998).

La posicionalidad (física y política) impactó en la forma de vida de las personas privadas de libertad. La acción misma de no aceptar un cambio de pabellón durante el periodo de vigencia del régimen cerrado podría terminar en una «lanchada»6, como indica el siguiente ejemplo de un solicitante:

En enero 1998, junto a otros reclusos del Pabellón 3-A destinado a internos pertenecientes al MRTA; el solicitante se negó ser reclasificado - [fue] trasladado junto a 21 integrantes de esa organización terrorista al Establecimiento Penal de Yanamayo en el departamento de Puno $(\mathrm{CAH}$, informe archivado, 17 de abril de 1998).

Aún en Yanamayo, hubo un espacio - aunque reducido- que albergaba a personas que se autodenominaban inocentes. Entre los indultos concedidos por la $\mathrm{CAH}$, menos de 20 de los 502, fueron otorgados a mujeres y hombres en Yanamayo. Los beneficiarios fueron principalmente hombres detenidos en las áreas rurales de Puno (Defensoría del Pueblo, 2001 [2000], Anexo 7: 141-167). Inicialmente este espacio se ubicaba en una parte del penal en el que también fueron internadas las personas organizadas con los grupos subversivos. A inicios de 1998, las autoridades abrieron una antigua sección en la cárcel y en febrero del mismo año, un solicitante de indulto escribió a su familia:

Nos han trasladado a este Penal a 20 personas, los mejores independientes, al Penal San Sebastián por tener buena Conducta» [Sintaxis del original] (CAH, expediente 590, caja 194, folios 073a y 073b).

Cuando representantes de la CVR fueron al penal de mujeres de Chorrillos, la delegada del Pabellón A, entre las demandas presentadas, reveló que «las ONG ya no apoyan. El pabellón se crea como un espacio que recibe a desvinculados [sic]» (CVR, [Manuscrito de reunión...], Expediente SCO-113-01). En su breve

6 «Lanchada» es la expresión usada en el argot de la cárcel para referirse a los traslados masivos de internos a penales de provincias, de una manera discrecional, y a veces arbitraria, realizados por parte de la autoridad penitenciaria. 
acercamiento, los/las representantes de la CVR notaron rápidamente que el histórico pabellón A —el lugar de «las inocentes»— en 2002 ya no albergaba inocentes, sino a desvinculadas7.

Desde el inicio del trabajo «en nombre de los inocentes», fue evidente para todos/ as los/las participantes, que el lugar colectivamente construido como «inocente» era un factor tomado en cuenta para el otorgamiento (o no) del indulto. «Algunos para poder pedir indulto cambiaron de pabellón» indicó la abogada antes citada (BB, 28 de agosto de 2012). Las mismas autoridades fueron artífices de los cambios de pabellón, como señala uno de los expedientes archivados:

Éste se encuentra ubicado en el pabellón 6 que alberga a internos que aún mantienen vínculos con la subversión. Cuando las autoridades del penal le propusieron el cambio de pabellón por medidas de seguridad el solicitante negó esta posibilidad por no considerarlo necesario $(\mathrm{CAH}$, informe archivado, 15 de mayo de 1998).

Con el transcurrir de los años aumentaron las solicitudes de indulto, concurrentemente con los impactos dejados por el régimen cerrado. El espacio físico de ciertos «lugares de inocencia» también cambió de significado. Ya no existía un lugar, sino varios. Ni siquiera vivir en ellos fue entonces indispensable para respaldar la aprobación de un indulto. Un expediente dice que el solicitante «fue ubicado en el pabellón 3-B, considerado como de mediana peligrosidad. Actualmente se encuentra alojado en el $2^{\mathrm{o}}$ piso del Pabellón 5-A, lugar en el que las autoridades penitenciarias han reunido un grupo de internos considerados 'independientes' para posteriormente conformar un nuevo pabellón piloto» (CAH, informe n. ${ }^{\circ}$ 007-99/CAH).

Hacia el final de la década, los pabellones de los «no inocentes» ya no tenían la misma valencia. Se iban transformando las definiciones anteriormente rígidas debido a los cambios (reglamentarios y de hecho) del régimen penitenciario y la salida de los/as internos/as por mandato del Poder Judicial o la Comisión Ad-Hoc.

Entonces, en el último año, cuando la comisión iba cerrando sus labores, creció la posibilidad de que la ubicación en un pabellón de «culpables» no impidiera un posible indulto.

\section{6. «ESTUVE PRESO Y ME VISITASTE»: EL ROL DE LA RELIGIÓN}

Aunque tautológicamente, en muchos penales la fe religiosa sirvió en el proceso de construcción de inocencia. Durante los años iniciales del régimen cerrado en los penales de Castro Castro y Chorrillos, por ejemplo, solo las personas ubicadas en ciertos lugares (los lugares de inocencia) pudieron colectivamente compartir su fe religiosa. Su ubicación era una conditio sine quo non de la expresión

7 Se usa el término desvinculado/a para referirse a aquellas personas que, habiendo pertenecido a alguno de los grupos subversivos, se alejaron de éste. Estas no reivindican «inocencia». 
colectiva del Catolicismo (y en menor medida, el Protestantismo). Algunos de los extractos de los expedientes indican: «se tiene conocimiento que hace vida cristiana» (CAH, informe n. ${ }^{\circ}$ 002-96/CAH); «participa en actividades religiosas» $\left(\mathrm{CAH}\right.$, informe n. ${ }^{\circ}$ 007-96/CAH); «es católica, asistiendo a los actos litúrgicos» $\left(\mathrm{CAH}\right.$, informe . $\left.^{\circ} 001-97 / \mathrm{CAH}\right)$; «participa en las actividades de grupos pastorales» $\left(\mathrm{CAH}\right.$, informe n. $\left.{ }^{\circ} 005-97 / \mathrm{CAH}\right) ;$ y «pertenece a la Iglesia Adventista del Séptimo Día» (CAH, informe n. $\left.{ }^{\circ} 009-97 / \mathrm{CAH}\right)$.

La asistencia a servicios religiosos podría ser vista como causa $-y$ también como efecto- de la inocencia. Existía una lógica, expresada en discursos y en actos performativos, que indicaba que aquellas personas que participaban en la misa eran inocentes. Esta dinámica fue tan conocida, que la misma gente que se autonombró inocente admitía su utilización estratégica. En una carta colectiva a favor de un solicitante de indulto, un grupo de personas ya indultadas señalaron:

XX nos dio muestras permanentes de ser contrario a toda propuesta violentista ajeno a las poses hipócritas de algunos interesados en aparentar una condición que nunca han tenido; siempre se le conoció como cristiano evangélico no solo por su palabra sino que también por su conducta $(\mathrm{CAH}$, expediente 439, caja 182).

\section{IZANDO LA INOCENCIA O EMBANDERANDO LA CULPABILIDAD}

Al interior de la cárcel, entre las múltiples prácticas que «demostraban»la inocencia o culpabilidad de una persona, se encuentra su relación con la bandera peruana y el himno nacional. Estas prácticas destacan por el hecho de que uno de los objetivos centrales de ambos grupos subversivos fue la construcción de una nueva nación y un nuevo Estado. Para el PCP-SL, este plan implicaba la destrucción del «viejo Estado», reemplazándolo con otro que tenía su propia bandera y sus propios cantos. En el argot de la cárcel, se habla de personas que «cantan» para señalar a alguien que proporciona información a las autoridades. En este caso, lo de cantar era literal: cantaban para demostrar inocencia. En numerosos testimonios otorgados a la CVR, mujeres y hombres narran cómo el himno fue empleado durante su detención en la DINCOTE, bases militares y/o durante su encarcelamiento en los diversos penales del país (CVR, testimonios 700025, 700069, 7000090, 7000091, 700095, 7000150, 7000256, 700263, 700300, 700320, 700321, 700343, 700357, 700424, 7000427, 700449, 700756, 700684, 700805 y 700906).

Entre muchos relatos similares, se puede citar al testimoniante 700320 que indica:

Con su arma nos tiraban en la cabeza, nos hacían cantar el himno nacional a cada piso de un pabellón (CVR, testimonio 700320).

Otra testimoniante relata:

Se sumaba a esto los chantajes de cantar el Himno Nacional si quieres mejores condiciones, eres o no peruana (CVR, testimonio 70091). 
Un resumen de la entrevistadora de la CVR dice:

El declarante manifiesta que en el penal ejercía la práctica de sacar a los internos de sus celdas, para cantar el himno nacional y efectuar el izamiento de la bandera (CVR, testimonio 700449).

Sin embargo, no se puede ver los símbolos patrios simplemente como métodos de castigo, sino accesorios en una performance en la cual todo el elenco participaba. La bandera peruana y el himno nacional fueron utilizados para proyectar una identidad hacia afuera de uno/a mismo/a, del pabellón y/o del penal. Como fueron tan aceptados por todos los actores, las personas que asumieron la posicionalidad de inocentes también los utilizaron.

En un expediente de solicitud de indulto se encuentra una carta colectiva de enero de 1997, dirigida al presidente Fujimori, por parte de personas que declaran su inocencia de cualquier vínculo con el MRTA. La misiva, escrita a mano, fue enviada a más de un mes de iniciada la crisis de la toma de rehenes en la residencia del embajador japonés por el MRTA. Los 14 firmantes, internos en el penal de Castro Castro, reiteran su inocencia, expresando su «total apoyo en la gestión que Ud. realiza por la Pacificación y Reconciliación Nacional», señalaron la conformación de «una comunidad cristiana en la mayoría de los casos» y luego hicieron mención de la compra de una bandera peruana:

Donamos un pabellón nacional para entonar las notas del Himno Nacional (CAH, expediente 588, caja 197, folios 882-884).

La mención de la bandera, igual que la religión $-\mathrm{y}$ más adelante, el hecho que fueran «asesorados por diversos organismos de DD. HH.»-, tenía la intención de distinguirse frente a «otros» que pudiesen tener diferente relación con los símbolos patrios8.

Un interno de Yanamayo, que posteriormente solicitó su indulto, escribió una carta, fechada el 21 de marzo de 1996, al Comandante del PNP que fungía de director del penal en ese momento, solicitando su deseo de ser traslado a Lima, indicando:

Existe una disposición del Gobierno de que todo condenado de 15 años a menos sean (sic) trasladados a la cárcel de su zona de residencia. Además yo no estoy de acuerdo con las ideas Monstruozas (sic) de SL y el MRTA. Y solamente tengo la bandera del Perú [sintaxis del original] $(\mathrm{CAH}$, expediente 590, caja 194, folios 073a y 073b).

Otro interno también recuerda los rituales cívicos en Yanamayo:

De setiembre hasta diciembre 93 hubo todos los días ceremonia de Izamiento de la Bandera en el patio del Penal (CAH, expediente 1613, caja 118).

8 Postulo que el MRTA mantenía una conexión mí(s)tica con los símbolos patrios, a diferencia del PCP-SL. La bandera emerretista es una adaptación de la bandera del Perú, solo difiriéndose por la imagen de Túpac Amaru, un fusil y una porra en la franja blanca en medio formando la letra $\mathrm{V}$; y en una acción llena de simbología intencional el MRTA en 1985 robó la bandera de San Martín del museo en Huaura. 
El hecho de forzar a las personas a cantar el himno nacional o a izar una bandera sirve para subrayar - y no naturalizar - cuán imaginaria es la construcción de una nación, unificada bajo una bandera, un presidente y una canción. Benedict Anderson incluye himnos — particularmente su canto en unísono-y banderas nacionales como elementos de las comunidades imaginadas (Anderson, 1983: 145). El premio —o castigo — relacionado con la bandera, aunque pueda ser cuestionable, pretendía servir al objetivo de imponer a las personas encarceladas la naturalidad de asumir al Perú como la madre patria. Valió, además, para separar a las personas «inocentes» de las «culpables». La conexión forjada a través de la bandera peruana era, en realidad, innatural y fomentaba el aspecto performativo y simulado de estas categorizaciones.

\section{LA «VERDAD» DE LOS «NO INOCENTES»}

El discurso sobre los inocentes no fue una producción aislada de otros/as actores/ as que no pudieron (o quisieron) formar parte de esta identidad colectiva. La producción del «inocente» implicaba la acción e inacción a través de discursos realizados desde distintos puntos de enunciación. Para poder recaudar mayor información para la sustentación de solicitudes, la CAH también consultó a personas que asumieron su responsabilidad penal-política y a otras que se acogieron a la ley de arrepentimiento.

Algunos de los expedientes detallan la dinámica en la cual estas declaraciones fueron solicitadas y posteriormente consideradas aceptables:

Me entrevisté con AA, quien manifestó que no ha hecho aún ningún escrito a favor de ZZ, porque no sabe cómo hacerlo y escribe mal. Ha quedado en coordinar con [abogada detenida por el PCP-SL], para hacer este descargo a favor de ZZ (CAH, expediente 2102, caja 183).

En la entrevista efectuada a los arrepentidos $X X$ y $Y Y$, ambos se ratificaron en señalar al solicitante como integrante de Sendero Luminoso $(\mathrm{CAH}$, informe archivado, 1998, s. f. exacta).

Es paradójico que en los expedientes de solicitud de indulto se cuestionara el uso de declaraciones de los/las «arrepentidos/as» durante el proceso judicial, mientras que estas personas fueron consideradas fiables para reforzar la culpabilidad y desmentir la inocencia del (de la) solicitante de indulto.

No obstante, no todos/as colaboraron en la construcción de la inocencia. Una mujer que se arrepintió, al responder sobre sus expectativas de la CVR, dice:

Que las ONG vean no sólo a los que son inocentes. Además que han sido 'inocentes entre comillas' porque no todos eran inocentes (CVR, testimonio 700007).

Esta mujer — nombrada en varios testimonios ofrecidos a la CVR por haber delatado a otras personas-, podía haber tenido cierta información que le permitía hacer tal aseveración. Otra testimoniante, «[c]omenta que los organismos de Derechos 
Humanos, las comisiones, siempre han ido al penal por los absolutamente 'inocentes', por los que ellos 'intuyen' son inocentes» (CVR, testimonio 700003). No existía uniformidad respecto al criterio con el cual ciertas declaraciones llegaron a ser provechosas, mientras que otras fueron desechadas. La inocencia fue una producción conjunta en la cual no hubo ningún «dramaturgo/a original», sino que hubo una creación dinámica, que incluía declaraciones estratégicas y/o silencios cómplices, para que algunas personas pudieran solicitar, y a veces recibir, el indulto.

\section{EL RÉGIMEN DE GÉNERO DE LA INOCENCIA}

La inocencia tuvo su propio régimen de género. Según Raewyn Connell, quien concibió el término, un régimen de género es el patrón de relaciones de género en una institución en particular y la continuación de ese patrón que produce «el contexto estructural de relaciones particulares y prácticas individuales» (Connell, 2005). El régimen de género de la inocencia fue similar, aunque con sus matices, de roles socialmente construidos entre mujeres y hombres en el Perú costeño y urbano. Los datos indican una diferencia notable entre hombres y mujeres respecto a las probabilidades de recibir un indulto. Las cifras finales de la $\mathrm{CAH}$ indican que el $87 \%$ de los solicitantes (3 374) fueron hombres y el $13 \%$ fueron mujeres (504) y entre el grupo de indultos, el $81 \%$ fueron otorgados a hombres (407) y el $19 \%$ a mujeres (95). A primera vista parece mínimamente favorable para las solicitantes mujeres. No obstante, realizando el cálculo para hombres, solo el 14 \% que solicitó un indulto lo recibió (407 de las 2813 solicitudes), mientras que esta figura sube a $23 \%$ para las mujeres (95 indultadas de las 412 solicitudes).

Existen otros indicios de una mayor factibilidad de los indultos a mujeres. Según la abogada BB, esto se debía a «la sociedad machista donde las mujeres somos vistas como más débiles, que pueden someternos, pueden convencernos, pueden persuadirnos» (BB, 28 de agosto de 2012). La perspectiva de De la Jara respecto a que las mujeres «llevaron la peor parte» del uso, manipulación y aprovechamiento de «vínculos sentimentales» por los subversivos» merece mayor matización (De La Jara, 2001: 274). Los indicios apuntan a que ellas tuvieron mayores posibilidades que los hombres de ser vistas como utilizadas por sus parejas heterosexuales, precisamente debido a estereotipos de género.

Una revisión de los expedientes indica el régimen de género creado en el cual las mujeres son caracterizadas como «buena[s], humilde[s], tranquila[s]» $(\mathrm{CAH}$, informe n. ${ }^{\circ}$ 010-96/CAH) y dedicadas a ciertas actividades. Aun cuando había sido señalada por tres arrepentidos, el expediente de una mujer que eventualmente recibió su indulto indica que ella «ha demostrado buena conducta, mostrándose disciplinada y respetuosa con las autoridades del penal. Realiza trabajos en peluches y diversas manualidades» (CAH, informe n. ${ }^{\circ}$ 011-97/CAH).

La maternidad, en este régimen de género, es contraria y excluyente de una opción política, y por ende demostrativa de la inocencia. En el caso de una mujer 
acusada de haber puesto un explosivo en un mercado el día que su hijo cumplía años, el abogado, al resumir su caso, escribe:

Resulta inverosímil pensar que un delincuente terrorista pueda estar preocupado en los preparativos de la fiesta infantil de su hijo como es el caso de la solicitante y a la vez llevar adelante actos terroristas colocando un artefacto explosivo (CAH, informe n. ${ }^{\circ}$ 010-97/CAH).

La solicitante fue descrita como «una madre de familia que para ayudar a la manutención de su hogar se dedicaba a la venta de comida. Tras la detención de su esposo en noviembre de 1992, asumió la responsabilidad de su hogar integrado por sus cuatro menores hijos» (CAH, informe n. $\left.{ }^{\circ} 010-97 / C A H\right)$.

Mientras que las mujeres fueron representadas como sumisas, diestras en manualidades y maternales, los hombres fueron representados como responsables, particularmente con sus familias (ya sea como hijos o como padres). Entre los varios casos, está el padre bonachón:

Obran en el expediente memoriales en los que describe al solicitante, como un padre de familia hogareño, responsable y querido por todos sus amigos (CAH, informe n. ${ }^{\circ}$ 004-97/CAH).

Un segundo solicitante está descrito en el expediente por otros:

Según sus vecinos y compañeros de trabajo, es un hombre de buen comportamiento, caracterizándose por ser tranquilo, cumplidor con sus deberes $\left(\mathrm{CAH}\right.$, informe $\left.n .^{\circ} 003-97 / \mathrm{CAH}\right)$.

La inocencia conllevaba cierta emasculación de los hombres. Hubo casos en los que alegaban haber sido engañados por mujeres, algo socialmente deplorable en otras circunstancias aunque, según el contexto, servía como una insignia de honor (e inocencia). Uno de los casos examinados es el de un hombre detenido con una senderista muy conocida, en un departamento que presuntamente servía como una base logística para Socorro Popular. En su expediente, los documentos señalan que todo se debía a que «trabó amistad y luego se inició una relación sentimental, sin saber que dicha persona está involucrada en 'SL'» y que ésta le había presentado a su compañera de habitación, quien era senderista $(\mathrm{CAH}$, expediente 613, caja 118).

Mientras que la figura de un hombre manipulado pone en cuestión su virilidad y capacidad de dominar al sexo opuesto, en los casos examinados solo parecían sufrir una baja temporal de su hombría. Por ejemplo, en el caso citado, el perfil de Don Juan era el motivo real de su caída; él señaló que el motivo de vivir fuera de la casa familiar: «se debió a problemas familiares de incomprensión por mi vida disoluta (mujeriego y trasnochadas)» $(\mathrm{CAH}$, expediente 613, caja 118). En el expediente de un hombre que fue detenido con su esposa en su casa, donde presuntamente se encontró diversos materiales subversivos, el solicitante arguyó que su detención se debía que una de sus varias amantes buscaba vengarse de él. Había terminado con una de ellas una semana anterior a su detención y «ella lo habría amenazado con vengarse» $(\mathrm{CAH}$, expediente 133, caja 64). Tal vez el asunto no sería llamativo si no fuera porque éste fue uno de los casos ampliamente 
mencionados en campañas de la época, hablándose de un «hermano cristiano» injustamente encarcelado.

\section{EL RUEDO DE RECONOCIMIENTO}

Las diferencias educativas, étnico-culturales y de clase estuvieron omnipresentes, aunque con valoraciones distintas — dependiendo del punto de vista-, para construir la inocencia y culpabilidad. El perfil de las personas indultadas tiene similitud con el que la DINCOTE (Dirección Nacional contra el Terrorismo) utilizó para sostener que alguien era terrorista. De la Jara indica:

A partir de algún rasgo, característica o condición encontrados en un número determinado de senderistas o emerretistas se pasa a generalizar, a asumir que toda persona» que los tenga es un terrorista (De La Jara, 2001: 282).

Haciendo un repaso de estas características para desbaratarlas como válidas, él menciona: ser ayacuchano, provinciano, habitantes de ciertos pueblos jóvenes limeños, estudiantes de ciertas universidades, así como profesionales de salud o derecho. Algunos rasgos llegaron a ser interpretados de manera opuesta como un indicio de culpabilidad o una afirmación de inocencia.

Según el informe final de la $\mathrm{CAH}, 25 \%$ de los indultados eran profesionales, estudiantes y empleados. El grupo más grande estaba compuesto de campesinos/ as, equivalente al $40 \%$ de las personas indultadas. Vale la pena acotar que el muy citado estudio de Denis Chávez de Paz, que proporciona un perfil de las personas sentenciadas por delitos de terrorismo entre 1983 y 1986 — desafortunadamente no hay estudios similares posteriores - reveló que los estudiantes alcanzaban el $24,6 \%$ y los profesionales el 4,4\%, Ilegando al $29 \%$ del total (Chávez de Paz, 1989: 44). Las cifras de actividades predetención no eran muy distantes entre el grupo de los «inocentes» y el de los «culpables».

La etnia y procedencia rural fueron señaladas sin mayor dilucidación como indicios de la ausencia de vínculos con la subversión. En uno de los expedientes, se arguyó la inocencia de una mujer analfabeta y quechuahablante acusada de matar a cinco campesinos — con presunta evidencia en su contra, que incluía declaraciones de testigos - en diciembre de 1991:

Las condiciones personales de la solicitante son incompatibles con una vinculación a actos $u$ organizaciones terroristas... La solicitante proviene de una zona convulsionada y azotada por terrorismo. Su edad, su carácter y la conducta mostrada durante su permanencia en los E[stablecimientos] P[enales] donde ha sido recluida demuestran su desvinculación con cualquier actividad delictiva. [...] Los hechos denunciados, y principalmente la ferocidad con que fueron asesinados los agraviados no resultan compatibles con la actitud pacífica e ingenua de una típica campesina de edad madura de nuestra serranía (CAH, informe n. ${ }^{\circ}$ 004-96/CAH).

Además del paternalismo étnico evidente, existían ciertas ideas preconcebidas sobre el perfil de las personas vinculadas a grupos subversivos. Es decir, esta solicitante 
viene de una región donde el PCP-SL estuvo activo, pero sus características no son compatibles con aquellas de una subversiva. Dentro de esta lógica falaz se deduce que los subversivos eran extraños a la zona, por ende, se fomenta una narrativa simplificada del conflicto y sus actores/as. Además, se añadía que «[s]u propia contextura física hace inverosímil que haya tenido la agilidad y la fuerza para asesinar a personas más fuertes y jóvenes que ella» (CAH, informe n. ${ }^{\circ}$ 004-96/CAH). Aparte de dar la impresión que existía un tipo de cuerpo y edad para ser subversiva, el empleo de estas características en los expedientes, puso en evidencia las concepciones que mantenían aquellos individuos e instituciones (mayormente basados en Lima) que abogaban por la inocencia de ciertas personas. Es decir, los grupos subversivos no pudieron contar con cierto perfil de personas entre sus filas y/o un/a habitante rural de bajo nivel de educación formal solo sería capaz de decidir y actuar de acuerdo a los roles que les han sido socialmente asignados. De esta manera, la situación de ellas/os termina reiterando su estatus de víctima, inocente o sujeto manipulable.

\section{LOS PLANOS DE (DE)CONSTRUCCIÓN}

Se concluye con unas ideas interconectadas sobre las implicancias de la creación y uso continuo del discurso de la inocencia. Primero, no hay esencias en las identidades que fueran creadas y empleadas durante el conflicto. La construcción de la identidad de «los inocentes» conllevaba un sinfín de actores/as y guiones a representar. Frente a la idea frecuentemente sugerida por los medios de comunicación y repetida por políticos buscando réditos (o viceversa) de que existe una esencia inmutable de «terrorista», este ensayo pone en cuestión estas categorías fijas. Es útil analizar por qué, luego de años de haber cumplido una pena privativa de libertad, estas personas siguen siendo «terroristas» mientras que otras que habían tenido algún tipo de vínculo con la subversión y fueron reincorporadas a sus comunidades sin haber pasado por instancias de justicia nacional, son concebidas de manera distinta.

Hay un discurso, con sus prácticas concomitantes, que privilegia la idea de que la única manera de demandar los derechos es desde una posicionalidad de inocencia. Parte de la controvertida sentencia de la Corte Suprema de Justicia (CSJ) de julio de 2012 en el caso del Grupo Colina —anulada en septiembre de 2012 por dicha Corte- sostenía que no fue parte del proceso jurídico determinar si las víctimas (las personas asesinadas extrajudicialmente en Barrios Altos, los desaparecidos en El Santa y el asesinado Pedro Yuari) eran inocentes (CSJ, Expediente n. ${ }^{\circ} 4104$ 2010, 20 de julio de 2012). Las pocas críticas que señalaron que esta parte de la decisión estuvo errada, no lo hicieron con la misma fuerza con que correctamente se censuró la negación de crímenes de lesa humanidad y la disminución de penas. El concepto de «los inocentes» no existe en otros conflictos armados internos. Es válido seguir la revisión crítica de las implicancias de este término en la agenda de derechos humanos y políticas públicas que responden a las secuelas del conflicto. 
La ley de reparaciones específicamente señala en su artículo 4 que «no son consideradas víctimas y por ende no son beneficiarios de los programas a que se refiere la presente Ley, los miembros de organizaciones subversivas» (Ley 28592, 29 de julio de 2005). Se necesita seguir con las investigaciones académicas y jurídicas que aporten ideas más matizadas de los conceptos víctima-victimario/a sin evadir las responsabilidades penales respectivas.

Es preciso recalcar que otras miradas a contracorriente en esta u otra materia relacionada al conflicto, no debe silenciarse bajo la supuesta lógica que así se evita ser «tontos útiles» de la subversión, o de avivar rencores en los sectores más recalcitrantes a afrontar todos los desafíos pendientes. Como está demostrado por las interminables acusaciones mutuas entre individuos y partidos políticos sobre quienes liberaron más «terroristas», no hay momento «ideal» para abordar éste y otros temas sensibles relacionados. Pero esto no lo hace menos necesario.

Al concluir, se quiere evocar al defensor más conocido y tal vez el artífice mismo de «los inocentes», el Padre Lanssiers. En su intervención a la audiencia temática de la CVR sobre la legislación antiterrorista y el debido proceso, dijo:

El problema de los indultados no puede ser tomado aisladamente, se inscribe dentro de un contexto, tiene un principio, un desarrollo y un fin. No estoy seguro que tenga un fin (Lanssiers, 4 de julio de 2002).

Yo tampoco.

\section{Agradecimientos}

Mi gratitud al IFEA y al Grupo Memoria del Instituto de Estudios Peruanos (IEP) por permitirme presentar versiones de este artículo. Quiero dar gracias a los dos evaluadores por sus aportes constructivos y un reconocimiento a las personas entrevistadas como parte de esta investigación, en particular a Pilar Coll (Q.E.P.D.) —a quien sigo extrañandoFinalmente, mis agradecimientos a Alberto Gálvez Olaechea, Lori Berenson, Luisa Dietrich Ortega, Martha Dietrich Ortega y Richard Kernaghan que no solamente me nutren con intercambios provocadores y textos nuevos, sino también me animan a seguir desarrollando mis investigaciones.

\section{Referencias citadas}

\section{Fuentes primarias}

\section{COMISION AD-HOC (CAH)}

Grabación audiovisual del cierre de la CAH, 30 de diciembre de 1999

Borrador del comunicado, 14 de febrero de 1997

CAH expedientes

Expediente 590, caja 194, folios 073a y 073b

Expediente 2102, caja 183 
CAH informes archivados

s. f., 1998

17 de abril de 1998

24 de abril de 1998

15 de mayo de 1998

CAH informes números

002-96/CAH

004-96/CAH

007-96/CAH

010-96/CAH

001-97/САH

003-97/CAH

004-97/CAH

005-97/CAH

009-97/CAH

010-97/CAH

$011-97 / \mathrm{CAH}$

005-99/CAH

007-99/САH

021-99/CAH

\section{COMISIÓN DE LA VERDAD Y RECONCILIACIÓN}

LANSSIERS, H., 2002 - Audiencia Pública Temática sobre Legislación Antiterrorista y Violación al Debido Proceso, 4 de julio de 2002.

[Manuscrito de reunión (febrero de 2002) con delegadas del Penal de Chorrillos], Expediente SCO-113-01

«Plan ad hoc para toma de testimonios a presos por terrorismo», s. f., Expediente SCO36001: Patrones de crímenes- Coordinaciones- Penales- Planes de trabajo

Testimonios 700003, 700007, 700025, 700069, 7000090, 7000091, 700095, 7000150, 7000256, 700263, 700300, 700320, 700321, 700343, 700357, 700424, 7000427, 700449, 700756, 700684, 700805 y 700906

\section{CORTE SUPREMA DE JUSTICIA}

Sala Penal Permanente, Ejecutoria Suprema del 20 de julio 2012 (Expediente n. ${ }^{4}$ 41042010).

\section{ENTREVISTAS}

Ernesto de la Jara, 1 de diciembre de 2010

Pilar Coll, 10 de diciembre de 2010

Edgar Rivadeneyra, 13 de diciembre de 2010 y 17 de agosto de 2012

BB, 28 de agosto de 2012

\section{LEGISLACIÓN Y SENTENCIAS}

Decreto Ley 25475, Ley de terrorismo, 6 de mayo de 1992 
Decreto Ley 25659, ley de traición a la patria, 12 de agosto de 1992

Decreto Ley 25499, Ley de arrepentimiento, 16 de mayo de 1992

Ley 26655, «Crea Comisión encargada de proponer al Presidente de la República la concesión de indulto a personas condenadas por delitos de terrorismo y traición a la patria», 16 de agosto de 1996

Ley 28592, «Ley que crea el Programa Integral de Reparaciones», 29 de julio de 2005

TRIBUNAL CONSTITUCIONAL

Expediente n. ${ }^{\circ}$ 0001-2002-AI Lima, Caso Marcelino Tineo Silva et al., enero de 2003

\section{Fuentes secundarias}

ANDERSON, B., 1983 - Imagined Communities. Reflections on the Origin and Spread of Nationalism, 160 pp.; Londres: Verso.

ASOCIACIÓN NACIONAL DE INOCENTES LIBERADOS, s. f. - Reseña histórica. Disponible en: http://www.oocities.com/anilpe/anil_02.html

BUTLER, J., 1990 - Performative Acts and Gender Constitution: An Essay in Phenomenology and Feminist Theory. In: Performing Feminisms: Feminist Critical Theory and Theatre (S.-E. Case, ed.): 270-282; Baltimore: Johns Hopkins University Press.

CHÁVEZ DE PAZ, D., 1989 - Juventud y Terrorismo. Características sociales de los condenados por terrorismo y otros delitos, 61 pp.; Lima: Instituto de Estudios Peruanos.

CONNELL, R., 2005 - Advancing gender reform in large-scale organisations: A new approach for practitioners and researchers. Policy and Society, 24 (4): 1-21. Disponible en: http://www.xyonline.net/sites/default/files/Connell,\%20Advancing\%20gender\%20 reform.pdf

COMISIÓN DE LA VERDAD Y RECONCILIACIÓN, 2003 - Informe final, Tomo VI.

CRÓNICA VIVA, 2010 - Liberados e indultados acusan de difamación a Jorge del Castillo. Disponible en: http:/www.cronicaviva.com.pe/index.php/politica/2-politica/851liberados-e-indultados-acusan-de-difamacion-a-jorge-del-castillo

DEFENSORÍA DEL PUEBLO, 2001 [2000] - La labor de la Comisión Ad-hoc a favor de los inocentes en prisión: logros y perspectivas, 220 pp.; Lima: Defensoría del Pueblo.

GUPTA, A. \& FERGUSON, J., 1992 - Beyond 'Culture': Space, Identity, and the Politics of Difference. Cultural Anthropology, Vol. 7, n. ${ }^{\circ}$ 1: 6-23.

JARA BASOMBRÍO, E. de la, 2001 - Memoria y batallas en nombre de los inocentes Perú 1992-2001, 842 pp.; Lima: Instituto de Defensa Legal.

PORTELLI, A., 2003 - Memoria e identidad. Una reflexión desde la Italia postfascista. In: Monumentos, memoriales y marcas territoriales (E. Jelin \& V. Langland, ed.): 165190; Madrid: Siglo XXI.

RENIQUE, J. L., 2003 - La voluntad encarcelada: las luminosas trincheras de combate de Sendero Luminoso del Perú, 177 pp.; Lima: Instituto de Estudios Peruanos.

TUAN, Y.-F., 2011 [1977] - Space and Place. The Perspective of Experience, 235 pp.; Minneapolis: University of Minnesota Press. 